\title{
Identification, synthesis and
} activity of sex pheromonegland components of the autumn gum moth (Lepidoptera:Geometridae), a defoliator of Eucalyptus

\section{Journal Article}

Author(s):

Steinbauer, Martin J.; Östrand, Fredrik; Bellas, Tom E.; Nilson, Anna; Andersson, Fredrik; Hedenström, Erik; Lacey, Michael J.; Schiestl, P. Florian

Publication date:

2004

Permanent link:

https://doi.org/10.3929/ethz-b-000422591

Rights / license:

In Copyright - Non-Commercial Use Permitted

Originally published in:

Chemoecology 14(3-4), https://doi.org/10.1007/s00049-004-0281-5 


\title{
Identification, synthesis and activity of sex pheromone gland components of the autumn gum moth (Lepidoptera: Geometridae), a defoliator of Eucalyptus
}

\author{
Martin J. Steinbauer ${ }^{1}$, Fredrik Östrand ${ }^{2}$, Tom E. Bellas ${ }^{3}$, Anna Nilsson ${ }^{4}$, Fredrik Andersson ${ }^{4}$, \\ Erik Hedenström ${ }^{4}$, Michael J. Lacey ${ }^{3}$ and Florian P. Schiestl ${ }^{5,6}$ \\ ${ }^{1}$ Co-operative Research Centre (CRC) for Sustainable Production Forestry and CSIRO Entomology, GPO Box 1700, Canberra, ACT 2601, Australia \\ ${ }^{2}$ Chemical Ecology and Ecotoxicology, Department of Ecology, Lund University, SE-223 62 Lund, Sweden \\ ${ }^{3}$ CSIRO Entomology, GPO Box 1700, Canberra, ACT 2601, Australia \\ ${ }^{4}$ Department of Natural and Environmental Sciences, Mid Sweden University, SE-851 70 Sundsvall, Sweden \\ ${ }^{5}$ Department of Evolutionary Biology, University of Vienna and School of Botany and Zoology, Australian National University, Canberra, ACT 0200, \\ Australia \\ ${ }^{6}$ Present address: Geobotanical Institute ETH, 107 Zollikerstrasse, CH-8008 Zürich, Switzerland
}

Summary. The autumn gum moth, Mnesampela privata (Guenée) (Lepidoptera: Geometridae), is native to Australia and can be a pest of plantation eucalypts. Field-collected and laboratory-reared female autumn gum moths were dissected to remove glands likely to contain components of the sex pheromone. Using gas chromatography (GC) and combined gas chromatography-mass spectrometry (GC-MS), three compounds were identified from female extracts, namely (3Z,6Z,9Z)-3,6,9-nonadecatriene, 1-hexadecanol and 1-octadecanol (confirmed by comparison with synthetic samples). Nonadecatriene elicited an antennal response in male autumn gum moth during gas chromatographic analyses combined with electroantennographic detection (GC-EAD). In electroantennogram (EAG) recording male $M$. privata antennae responded to the nonadecatriene. Nonadecatriene was synthesised via Kolbe electrolysis, starting with $(9 Z, 12 Z, 15 Z)$-octadeca-9,12,15-trienoic acid (linolenic acid) and propanoic acid or via an alternative four-step method also starting from linolenic acid. In field trials $(3 Z, 6 Z, 9 Z)-3,6,9$-nonadecatriene proved attractive to male moths. Thus, we conclude that $(3 Z, 6 Z, 9 Z)-3,6,9$ nonadecatriene is a sex pheromone component of autumn gum moth. This component has been identified in extracts from other geometrids in the same subfamily, Ennominae. However, to our knowledge this is the first example where $(3 Z, 6 Z, 9 Z)-3,6,9$-nonadecatriene has been found in females and also proved attractive to male moths when presented on its own. Our results are discussed in relation to other geometrid pheromones.

Key words. (3Z,6Z,9Z)-3,6,9-nonadecatriene - gas chromatography-mass spectrometry - GC-EAD - EAG - synthesis

Correspondence to: Martin Steinbauer, e-mail: Martin.Steinbauer@csiro.au

\section{Introduction}

Mnesampela privata is an endemic Australian moth whose larvae feed upon species of Eucalyptus (McQuillan 1985). The peak season of moth activity is typically from late February until mid April, and the larvae appear shortly after adult emergence (Elliott \& Bashford 1978; Steinbauer et al. 2001; Steinbauer 2003).

Among the most preferred eucalypt hosts of $M$. privata are the species E. globulus and E. nitens (both are commonly referred to as bluegums). Coincidentally, these two species are among the most important species used in commercial plantations in Australia. There has been rapid, largescale and widespread planting of these two eucalypts in south-eastern and south-western Australia over the last decade. The autumn gum moth represents a threat to this industry and has become one of the most significant outbreak insects of plantation eucalypts in south-eastern Australia (Abbott 1993; Bashford 1993; Neumann 1993; Phillips 1993; Stone 1993; Elliott et al. 2000). The leaves of these eucalypts are only attractive to adults while they are still juvenile (Steinbauer 2002); after 3-4 years (depending on the species and site) the foliage changes to adult leaves. Consequently, plantation bluegums only need to be protected from $M$. privata larvae for the duration of this stage of their growth.

Autumn gum moth larvae are usually controlled using aerial applications of alpha-cypermethrin (Neumann \& Collett 1997). The use of a sex pheromone for monitoring moth populations could be part of a more environmentally sustainable management strategy for this insect. Presently, populations of the autumn gum moth are usually monitored using more labour-intensive methods, either by counts of "hot spots" (i.e. leaves skeletonised by feeding of first instar larvae) or by defoliation estimates of whole trees (J. Bulinski \& J. Elek pers. comm.). 


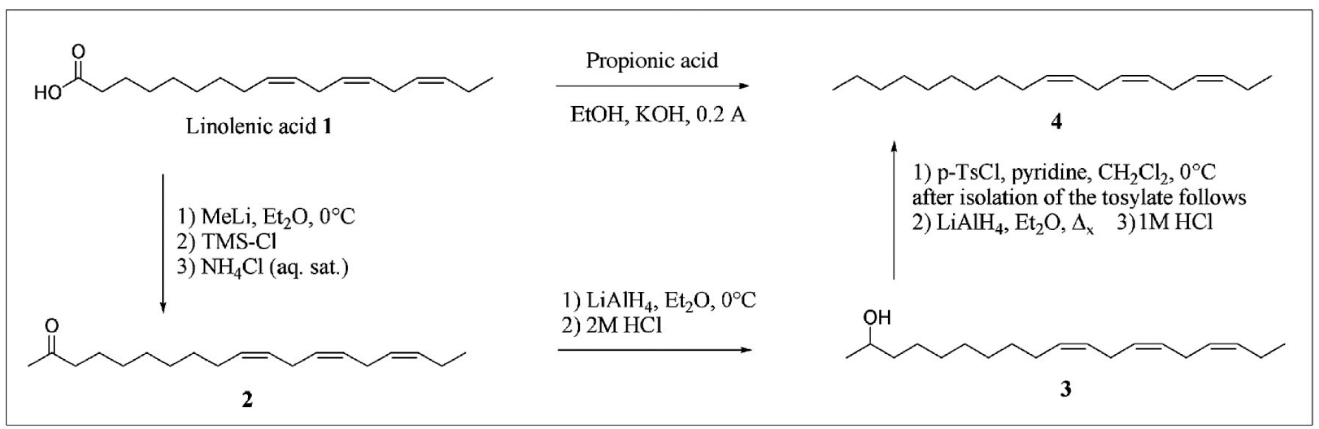

Schema 1 Two different synthetic routes to $(3 Z, 6 Z, 9 Z)$ 3,6,9-nonadecatriene ("4"), both starting from 9Z,12Z,15Z)octadeca-5,8,11-trienoic acid (linolenic acid "1")
The purpose of this study was to identify the sex pheromone of autumn gum moth. This entailed chemical analyses of female glands, recording of male antennal response, and field screening with synthetic replica compounds. The need for replica compounds offered the opportunity to investigate novel methods of synthesis.

\section{Materials and methods}

\section{Insects}

In 1999139 female pupae were collected from a plantation of E. grandis near Mildura, Victoria $\left(34^{\circ} 17^{\prime} \mathrm{S} 142^{\circ} 05^{\prime} \mathrm{E}\right)$. Pupae were also reared from eggs collected at Cornelian Bay, Tasmania (42 $\left.51^{\prime} \mathrm{S} 147^{\circ} 18^{\prime} \mathrm{E}\right)$ in 2000 and Ginninderra Experiment Station,

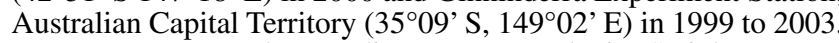
Larvae were reared according to protocols in Steinbauer and Matsuki (2004).

Sexed pupae were kept at $18{ }^{\circ} \mathrm{C}, 24 \mathrm{~h}$ scotophase and ambient humidity until ommatidia and wing pads had darkened. Near eclosion pupae were placed in individual containers in a controlled temperature cabinet set to a $12 \mathrm{~h}: 12 \mathrm{~h}$ light cycle. The temperature in this cabinet stayed within $16-19^{\circ} \mathrm{C}$.

\section{Chemical analyses}

Extract preparation: Results of analyses of pupae from different geographic locations are not reported separately. One- to two-day old virgin female moths were placed in a freezer for 4 to $5 \mathrm{~min}$ The ovipositor, with as little other tissue as possible, was removed and placed in a small tube with $20-30 \mu \mathrm{L}$ of HPLC-grade hexane. The tube was capped with aluminium foil and stored in a freezer. The extracts were refined by a mild thermal desorption technique (Whittle et al. 1991). The hexane extract was injected onto glass beads tightly packed in a tube, and the hexane was evaporated in a stream of nitrogen, $20 \mathrm{~mL} / \mathrm{min}$, at room temperature. The tube was placed in a small oven arranged so that a stream of helium passed through the tube at $12 \mathrm{~mL} / \mathrm{min}$. The oven was maintained at around $135^{\circ} \mathrm{C}$. The effluent from the tube was trapped in a capillary tube $(150 \mathrm{~mm}$ x $1.6 \mathrm{~mm})$ cooled with solid $\mathrm{CO}^{2}$. Desorption was conducted for 8 to $15 \mathrm{~min}$. The condensate was removed from the capillary walls in $2 \mu \mathrm{L}$ solvent (hexane or dichloromethane) prior to analysis.

Gas chromatography of pheromone extracts: GC analyses were conducted using a Carlo Erba Model 5300 instrument. Two columns were used: BP1 (dimethylsiloxane), $25 \mathrm{~m} \times 0.32 \mathrm{~mm}$ id phase thickness $0.25 \mu \mathrm{m}$; and BP10 (14\% cyanopropylphenyl polysiloxane) $25 \mathrm{~m} \times 0.32 \mathrm{~mm}$ id, phase thickness $0.25 \mu \mathrm{m}$; both supplied by SGE, Melbourne. The injection was on-column. The sample was injected over approximately $1 \mathrm{~min}$ at $60^{\circ} \mathrm{C}$. After 6 min the temperature was raised as quickly as possible (nominally at $49.9^{\circ} \mathrm{C}$ per min) to $200{ }^{\circ} \mathrm{C}$ and maintained at that temperature for the duration of the run. Retention data were collected on an integrator
(HP 3392A). Retention indices were calculated from runs in which hydrocarbon standards (for BP1 17, 18, 20 and 21 and for BP10 18, 20 and 22) were co-injected and calculations done using the program INDEX.

Gas chromatography-mass spectrometry: GC-MS analyses were undertaken using a VG Trio 2000 mass spectrometer interfaced directly to a Hewlett Packard 5890 Plus gas chromatograph and PC-based MassLynx software. Electron ionisation (EI) mass spectra were obtained at an ionisation voltage of $70 \mathrm{eV}$ and a source temperature of $180{ }^{\circ} \mathrm{C}$. The GC column used was a BPX35 (bonded-phase $35 \%$ phenyl polysilphenylene-siloxane, SGE, Australia), $30 \mathrm{~m} \times 0.32 \mathrm{~mm}$ id, phase thickness $0.25 \mu \mathrm{m}$. The column was preceded by a retention gap (length $3 \mathrm{~m}$ ), and samples were introduced using cool on-column injection. After 2 min at $40^{\circ} \mathrm{C}$, the column was programmed at $20^{\circ} \mathrm{C} / \mathrm{min}$ to $150^{\circ} \mathrm{C}$ then at $10{ }^{\circ} \mathrm{C} / \mathrm{min}$ to $300{ }^{\circ} \mathrm{C}$, followed by an isothermal period of $10 \mathrm{~min}$. Pheromone extracts and standards were dissolved in HPLC grade dichloromethane.

\section{Syntheses}

The (3Z,6Z,9Z)-3,6,9-nonadecatriene ("4" in Schema 1) has earlier been synthesised using different strategies (reviewed in Millar 2000). Initially, we applied Kolbe electrolysis (see Schema 1) starting from pure linolenic acid and propionic acid using $\mathrm{MeOH}$ as solvent (Bestmann et al. 1987). This method is known to result in low yields (Millar 2000; references therein) and we obtained a complex mixture of products from which it was difficult to isolate a pure product, but after altering the voltage and changing to EtOH as solvent, we obtained a more easily purified product mixture. This gave us a small amount of pure (> $98 \%$ by GC) nonadecatriene "4" that was needed at that time. Analytical and spectroscopic data were identical with the product obtained below.

When more nonadecatriene was needed for biological purposes we developed an alternative method (as described below and in Schema 1), again starting from linolenic acid which was reacted with an excess of methyl lithium (Rubottom \& Kim 1983) to produce the corresponding ketone " 2 " at $61 \%$ yield. After reduction with $\mathrm{LiAlH}_{4}$, the secondary alcohol " 3 " was obtained in near quantitative yield. The alcohol was then converted to a tosylate which, when followed by $\mathrm{LiAlH}_{4}$ reduction (Kabalka et al. 1986), produced nonadecatriene at $>98 \%$ purity. Specific details about each stage of the syntheses are presented below.

(10Z,13Z,16Z)-nonadeca-10,13,16-trien-2-one ("2”): The alkylation follows that described by Rubottom \& Kim (1983) for other types of acids. $(9 Z, 12 Z, 15 Z)$-octadeca-9,12,15-trienoic acid $(2.83 \mathrm{~g}, 10.2 \mathrm{mmol})$ was dissolved in dry $\mathrm{Et}_{2} \mathrm{O}(75 \mathrm{~mL})$ and cooled to $0{ }^{\circ} \mathrm{C}$. Methyl lithium (1.6 $\mathrm{M}$ in $\mathrm{Et}_{2} \mathrm{O}, 31.7 \mathrm{~mL}, 50.8 \mathrm{mmol}$ ) was added to this solution, and stirring was continued at $0{ }^{\circ} \mathrm{C}$. After $2.3 \mathrm{~h}$ TMS-Cl $(6.45 \mathrm{~mL}, 50.8 \mathrm{mmol})$ was added to the reaction mixture, and the mixture was allowed to reach room temperature, then aqueous saturated $\mathrm{NH}_{4} \mathrm{Cl}(50 \mathrm{~mL})$ was added and stirring continued for another $0.5 \mathrm{~h}$. The organic phase was separated, and the aqueous phase was extracted with $\mathrm{Et}_{2} \mathrm{O}(3 \times 50 \mathrm{~mL})$. The combined ether 
extracts were washed with aqueous saturated $\mathrm{NaHCO}_{3}(50 \mathrm{~mL})$, $\mathrm{H}_{2} \mathrm{O}(50 \mathrm{~mL})$ and dried $\left(\mathrm{MgSO}_{4}\right)$. Evaporation of the solvent gave $3.08 \mathrm{~g}$ of the product along with some tertiary alcohol (ketone:tertiary alcohol, 3:1). Flash chromatography (EtOAc/ cyclo-hexane) gave the ketone "2", a yellow oil, in $61 \%$ yield and $99 \%$ purity by GC (1.71 g, $6.19 \mathrm{mmol}) .{ }^{1} \mathrm{H}$ NMR $250 \mathrm{Mhz}$ $\left(\mathrm{CDC}_{13}\right): \delta 0.98(3 \mathrm{H}, \mathrm{t}, J=7.5 \mathrm{~Hz}), 1.23-1.37(8 \mathrm{H}, \mathrm{m}), 1.51-1.63$ $(2 \mathrm{H}, \mathrm{m}), 2.02-2.11(4 \mathrm{H}, \mathrm{m}), 2.14(3 \mathrm{H}, \mathrm{s}), 2.42(2 \mathrm{H}, \mathrm{t}, J=7.4 \mathrm{~Hz})$, 2.78-2.83 (4H, m), 5.26-5.46 (6H, m). ${ }^{13} \mathrm{C}$ NMR $62.9 \mathrm{MHz}$ $\left(\mathrm{CDC}_{13}\right): \delta 14.3,20.6,23.8,25.5,25.6,27.2,29.1$ (2C), 29.3, 29.6, $29.9,43.8,127.1,127.7,128.3(2 \mathrm{C}), 130.3,132.0,209.4$. MS (CI) $\mathrm{m} / \mathrm{z}$ (relative intensity): $277\left(\mathrm{MH}^{+}, 46 \%\right), 276\left(\mathrm{M}^{+}, 6\right), 189(42), 177$ (100), 163 (93), 149 (58), 135 (63), 123 (90), 109 (92), 95 (83), 81 (63). Anal. Calcd. For $\mathrm{C}_{10} \mathrm{H}_{32} \mathrm{O}: \mathrm{C}, 82.6 ; \mathrm{H}, 11.4$. Found: $\mathrm{C}, 82.4 ; \mathrm{H}, 11.5$. (10Z,13Z,16Z)-nonadeca-10,13,16-trien-2-ol ("3"): The ketone "2" (1.64 g, $5.94 \mathrm{mmol})$ was dissolved in dry Et $\mathrm{O}(25 \mathrm{~mL})$ and cooled to $0{ }^{\circ} \mathrm{C}$, followed by addition of $\mathrm{LiAlH}_{4}(225 \mathrm{mg}, 5.94$ $\mathrm{mmol}$ ). After $1.5 \mathrm{~h}$ the reaction was quenched with aqueous $2 \mathrm{M}$ $\mathrm{HCl}$. The organic phase was separated and the aqueous phase was extracted with $\mathrm{Et}_{2} \mathrm{O}(5 \times 25 \mathrm{~mL})$. The combined ether extracts were washed with brine $(50 \mathrm{~mL}), \mathrm{H}_{2} \mathrm{O}(50 \mathrm{~mL})$ and dried $\left(\mathrm{MgSO}_{4}\right)$ Evaporation of solvent gave $1.58 \mathrm{~g}$ of the title compound, which after flash chromatography ( $\mathrm{Et}_{2} \mathrm{O} /$ pentane) gave the alcohol " 3 ", a yellow oil, in $93 \%$ yield and $99.5 \%$ purity by GC $(1.53 \mathrm{~g}, 5.50$ mmol). ${ }^{1} \mathrm{H}$ NMR $250 \mathrm{MHz}\left(\mathrm{CDCl}_{3}\right): \delta 0.98(3 \mathrm{H}, \mathrm{t}, J=7.5 \mathrm{~Hz}), 1.19$ $(3 \mathrm{H}, \mathrm{d}, J=6.2 \mathrm{~Hz}), 1.23-1.42(13 \mathrm{H}, \mathrm{m}), 2.02-2.14(4 \mathrm{H}, \mathrm{m})$, $2.75-2.87(4 \mathrm{H}, \mathrm{m}), 3.73-3.85(1 \mathrm{H}, \mathrm{m}), 5.26-5.46(6 \mathrm{H}, \mathrm{m}) .{ }^{13} \mathrm{C} \mathrm{NMR}$ $62.9 \mathrm{MHz}\left(\mathrm{CDCl}_{3}\right): \delta 14.3,20.6,23.5,25.5,25.6,25.8,27.2,29.2$, 29.5, 29.6 (2C), 39.4, 68.2, 127.1, 127.7, 128.3 (2C), 130.3, 132.0. MS (CI) $m / z$ (relative intensity): $279\left(\mathrm{MH}^{+}, 21 \%\right), 278\left(\mathrm{M}^{+}, 4\right)$ $261\left(\mathrm{MH}^{+}-\mathrm{H}_{2} \mathrm{O}, 55\right), 191$ (42), 177 (50), 163 (60), 149 (66), 135 (63), 123 (75), 109 (100), 95 (75). Anal. Calcd. For $\mathrm{C}_{19} \mathrm{H}_{34} \mathrm{O}: \mathrm{C}$, 82.0; $\mathrm{H}, 12.3$. Found: $\mathrm{C}, 81.6 \cdot \mathrm{H}, 11.9$

(3Z,6Z,9Z)-nonadeca-3,6,9-triene( " 4 "): The tosylation followed that described by Kabalka et al. (1986) for other alcohols. Alcohol "3" (1.45 g, $5.20 \mathrm{mmol})$ was dissolved in dry $\mathrm{CH}_{2} \mathrm{Cl}_{2}$ $(10 \mathrm{~mL})$ and cooled to $0{ }^{\circ} \mathrm{C}$, followed by addition of dry pyridine $(1.26 \mathrm{~mL}, 15.6 \mathrm{mmol})$ and $\mathrm{p}$-toluenesulphonyl chloride $(1.98 \mathrm{~g}$, $10.4 \mathrm{mmol})$. After stirring at $0{ }^{\circ} \mathrm{C}$ for $44 \mathrm{~h}, \mathrm{Et}_{2} \mathrm{O}(40 \mathrm{~mL})$ and $\mathrm{H}_{2} \mathrm{O}$ $(10 \mathrm{~mL})$ was added to the reaction mixture and the aqueous phase was removed. The organic phase was washed with aqueous $2 \mathrm{M}$ $\mathrm{HCl}(10 \mathrm{~mL})$, aqueous saturated $\mathrm{NaHCO}_{3}(10 \mathrm{~mL}), \mathrm{H}_{2} \mathrm{O}(10 \mathrm{~mL})$ and dried $\left(\mathrm{MgSO}_{4}\right)$. After evaporation of the solvent the crude product was purified by flash chromatography (EtOAc/cyclohexane), which yielded $1.83 \mathrm{~g}$ (approx. $88 \%$ purity by GC) of the tosylate.

The crude tosylate $(1.83 \mathrm{~g})$ was dissolved in dry $\mathrm{Et}_{2} \mathrm{O}$ and $\mathrm{LiAlH}_{4}$ (262 mg, $6.87 \mathrm{mmol}$ ) was added. After refluxing for $8 \mathrm{~h}$, the reaction mixture was cooled to $0{ }^{\circ} \mathrm{C}$ and quenched with aqueous $1 \mathrm{M} \mathrm{HCl}$. The organic phase was separated and the aqueous phase was extracted with $\mathrm{Et}_{2} \mathrm{O}(3 \times 40 \mathrm{~mL})$. The combined ether extracts were washed with aqueous saturated $\mathrm{NaHCO}_{3}(75 \mathrm{~mL})$, brine $(75 \mathrm{~mL}), \mathrm{H}_{2} \mathrm{O}(75 \mathrm{ml})$ and dried $(\mathrm{MgSO})$. Evaporation of the solvent gave a yellow oil, which was purified by flash chromatography using $\sim 10$ wt. $\% \mathrm{AgNO}_{3}$ on silica gel $\left(\mathrm{Et}_{2} \mathrm{O} /\right.$ pentane $)$. The triene was obtained as an oil in $32 \%$ yield from the alcohol and with $98 \%$ purity by GC (435 mg, $1.66 \mathrm{mmol}) .{ }^{1} \mathrm{H}$ NMR data were similar to those in Bestmann et al. (1987). ${ }^{13} \mathrm{C}$ NMR $62.9 \mathrm{MHz}$ $\left(\mathrm{CDC}_{13}\right): \delta 14.1,14.3,20.5,22.7,25.5,25.6,27.2,29.3$ (2C), 29.5, $29.6,29.7,31.9,127.1,127.6,128.2,128.3,130.4,131.9$. MS (EI) data were identical to those in Millar (2000).

\section{GC-EAD and EAG studies}

Combined pheromone gland extracts ( 3 females, $6 \mu \mathrm{L}$ ) were injected on-column at $40{ }^{\circ} \mathrm{C}(1 \mathrm{~min})$ into a gas chromatograph (Varian 3400) followed by programming to $300{ }^{\circ} \mathrm{C}$ at a rate of $10{ }^{\circ} \mathrm{C}$ per min. The GC was equipped with an EC-1 column (dimethylpolysiloxane), $30 \mathrm{~m} \times 0.32 \mathrm{~mm}$ id, phase thickness $0.25 \mu \mathrm{m}$. Helium was used as a carrier gas. A GC effluent splitter (SGE, Australia; split ratio 1:1) was used, and the outlet was added to a purified and humidified air stream, directed over the excised antenna of a male moth. The tip of the antenna was cut off and the antenna mounted on an antennal holder using electrode gel. The electrode holding the base of the antenna was grounded. The distal end of the antenna was connected via an interface box (Syntech, Hilversum, the Netherlands) to a PC. EAD signals and flame ionization detector (FID) responses were simultaneously recorded. Another two GC-EAD runs were conducted each with $2 \mu \mathrm{L}$ of sample ( 1 female equivalent) extracted from individual females.

A GC-EAD active compound, namely (3Z,6Z,9Z)-3,6,9nonadecatriene (following identification from the GC and GC-MS data), was validated by co-injection of the synthetic analogue.

For EAG recordings male antennae were prepared as described above for the GC-EAD recordings, and the same type of interface was used. The cut antennae (including the tip) were placed between two electrodes that were made of thin glass capillaries filled with Ringer solution. The antennae were continuously exposed to charcoal-filtered and moistened air with a flow of $0.5 \mathrm{~m} / \mathrm{s}$. Stimuli were injected into the air stream through an opening in the glass tube $20 \mathrm{~cm}$ upstream from the antennae, with the outlet $1 \mathrm{~cm}$ from the antennae. Stimuli were administered by a device (Murphy Developments, Hilversum, the Netherlands) that delivered a $0.5 \mathrm{~s}$ puff of air at a flow rate of $5 \mathrm{~mL} / \mathrm{s}$. Our "standard stimulus" was prepared by dissolving hexane only onto a piece of filter paper placed in a Pasteur pipette and delivering air from this using the above mentioned device to the antennae. Prior to the experiments the solvent was allowed to evaporate. Synthetic samples, dissolved in hexane, were administered in the same way. An EAG recording comprised the sequential delivery of a standard stimulus, two synthetic samples and a standard stimulus. EAG recordings were analysed using 'EAG version 2.2a' (Syntech, The Netherlands 1993).

\section{Field trials}

The (3Z,6Z,9Z)-3,6,9-nonadecatriene used in field trials during 2002 and 2003 was synthesised by AN, FA and EH at Mid Sweden University, Sweden. The 1-hexadecanol (97\% purity) and 1 octadecanol (98\% purity) were recrystallised commercial samples.

From early February to mid April 2002, two field sites within the ACT were used. Lyneham Ridge $\left(35^{\circ} 14^{\prime} \mathrm{S} 149^{\circ} 07^{\prime} \mathrm{E}\right)$ is a 0.27 ha E. globulus plantation established in 1994. The trees were felled in 1999 to induce coppice. Ginninderra is a 0.69 ha plantation established in 1998 that comprises E. globulus and E. nitens as well as other species of Eucalyptus. All the E. globulus and $E$. nitens in these two plantations were in juvenile foliage at the time of the field tests.

Unitraps (Phero Bank, the Netherlands) filled with soapy water were hung from purpose-built poles approximately $1.4 \mathrm{~m}$ above the ground and spaced at least $10-15 \mathrm{~m}$ from one another. As dispensers, $4 \mathrm{~cm}$ lengths of medical rubber tubing of approximately $4 \mathrm{~mm}$ id (Graham Rubber, Granville, USA) were used. The synthetic triene and alcohols were dissolved in hexane, the solution allowed to soak into the rubber tubing and the solvent allowed to evaporate. Virgin females used in the field tests were placed in the same lure holder (a small basket with a cap) as the rubber septa. On some occasions, instead of emerged females, single pupae (with the moth close to emergence) were placed in the trap.

In 2003, aluminium foil was wrapped around the rubber septa to protect the pheromone components from degradation through exposure to the sun. Elsewise, dispensers were prepared as in 2002 In 2003 we also used blank (unbaited) traps on some occasions. Unitraps hung from poles of the same height were either filled with soapy water, $40 \%$ ethanol or the lower half of the trap was sprayed with an insecticide (Baygon, Bayer, Pymble NSW). All traps were placed at least $25-30 \mathrm{~m}$ from each other and their position was shifted when $>10$ moths had been caught in the best trap within each set-up.

Apart from the two plantations in the ACT, we also used a plantation of $E$. grandis in Victoria where an outbreak of M. privata was in progress during 2003. This gave us a chance to test the lures at a high population density site. This 1.4 ha plantation was established in 2001 and approximately $30 \%$ of the trees' foliage were juvenile. The baits were prepared as in 2002 , and the Unitraps were hung from poles at the same height. Catches were analysed with Kruskal-Wallis ranking tests, followed by Mann-Whitney tests for pair-wise comparisons. 


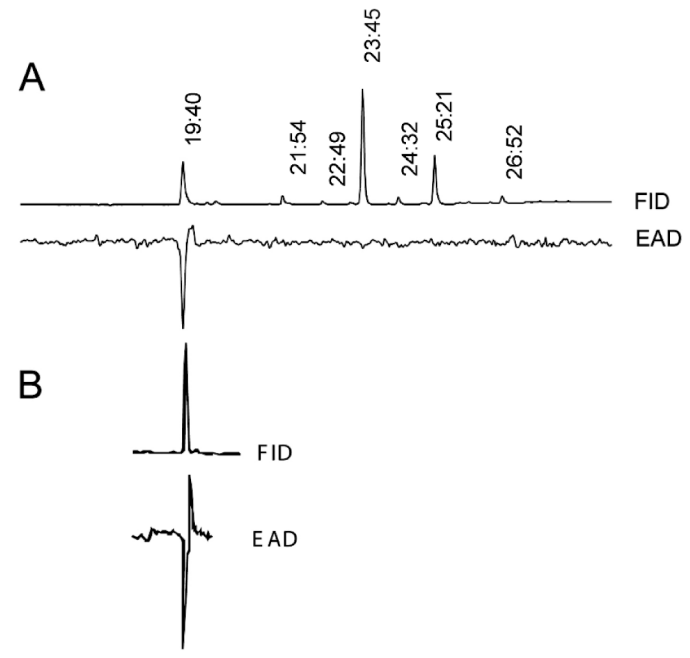

Fig. 1 Gas chromatographic analyses (FID) of (A) a female M. privata pheromone gland extract and (B) synthetic $(3 Z, 6 Z, 9 Z)$ 3,6,9-nonadecatriene with electroantennographic detection (EAD) using male antennae (note, $\mathbf{B}$ is aligned to time interval given for corresponding peak in A). One electrophysiologically-active component of the female extract eluted, in this instance, at a retention time of $19.40 \mathrm{~min}$. Another 6 compounds (mainly straight hydrocarbons, $\mathrm{C}_{21}-\mathrm{C}_{27}$ ) in the extract shown in $\mathbf{A}$ did not elicit an electrophysiological response in the male antenna

\section{Results}

Identification of electrophysiologically-active pheromone components

Using GC-EAD we observed a strong response of male $M$. privata antennae to the peak eluting from the GC column at a retention time of $19.40 \mathrm{~min}$ (Fig. 1A). None of the other peaks in the chromatogram were found to elicit an EAD reaction. The identities of the principal components of the extracts from $M$. privata females were established because they coincided precisely with the synthetic analogues of $(3 Z, 6 Z, 9 Z)-3,6,9$-nonadecatriene, 1-hexadecanol and 1-octadecanol, both in their EI mass spectra and their GC retention times on columns of low and high polarities. The other components in significant abundance were identified as a homologous series of saturated hydrocarbons. The symmetrical GC peak shape for the natural triene was maintained throughout the range of phase polarities, indicating that other stereo- or regio-isomers of the $(3 Z, 6 Z, 9 Z)$-triene were not present in any significant amounts. In addition, there was no detectable amount evident of an analogous heptadecatriene. The antennae of male moths responded both to the natural component and to synthetic $(3 Z, 6 Z, 9 Z)$ 3,6,9-nonadecatriene in GC-EAD runs (Fig. 1B).

Selected monitoring of diagnostic ions in their EI mass spectra $(\mathrm{m} / \mathrm{z}, 252.2,224.2,196.2,125.1,111.1,97.1,83.1)$ demonstrated that the relative proportion of $(3 Z, 6 Z, 9 Z)-3,6,9-$ nonadecatriene, 1-hexadecanol and 1-octadecanol fluctuated markedly between individual female extracts. That is, the ratios of (3Z,6Z,9Z)-3,6,9-nonadecatriene, 1-hexadecanol and 1-octadecanol fluctuated markedly between individuals (This variation in composition may be due to the age of the moths, whether or not they had begun release of pheromone

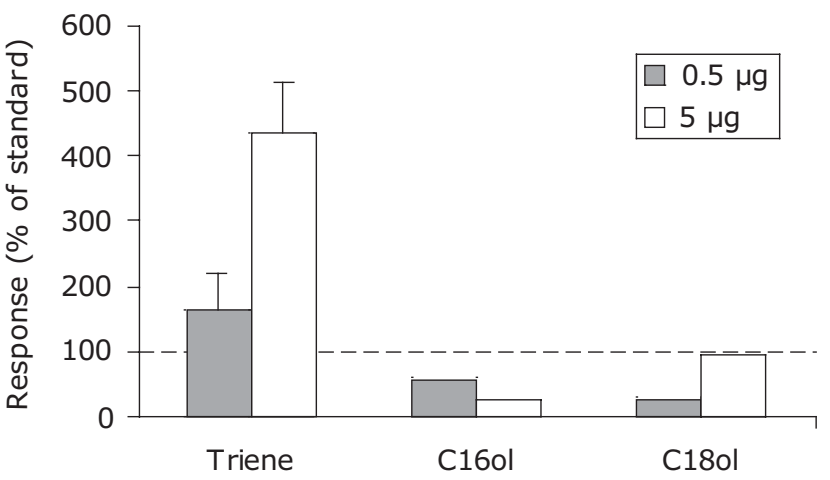

Fig. 2 Results of EAG recordings of male $M$. privata antennae to different compounds found in female extracts. Response ( \pm standard deviation) is expressed as a \% of the "standard stimulus" (see text). "triene" is short for $(3 Z, 6 Z, 9 Z)-3,6,9$-nonadecatriene and " $\mathrm{C}_{16} \mathrm{ol}$ " and " $\mathrm{C}_{18} \mathrm{ol}$ " are short for 1-hexadecanol and 1-octadecanol, respectively. In all cases $n=2$ except for " $\mathrm{C}_{16} \mathrm{ol}$ " and " $\mathrm{C}_{18} \mathrm{Ol}$ " where $n=1$

and/or their geographic origins). Typically, the triene was found by GC and GC-MS in all female extracts whereas either or both of the alcohols were not always detected in the extracts. The amount of triene in individual females varied up to approximately $110 \mathrm{ng}(n=19)$ (as judged by the size of the peaks on the chromatograms).

The alcohols and the triene were also examined for activity in male antennae during electroantennogram recordings (EAG). The triene again elicited a response, whereas neither of the alcohols elicited an antennal response different from that of a blank stimulus (Fig. 2).

\section{Field trials}

In the low-density areas (i.e. Lyneham Ridge and Ginninderra, ACT), the traps baited with virgin females caught some males, although the catch of individual females varied considerably (Table 1). The majority of virgin females (8 of 12) caught none or only one male during their time in the trap. With the exception of one female, which attracted 48 males over three consecutive nights, virgin females did not catch more males than did the traps baited with the synthetic (3Z,6Z,9Z)-3,6,9-nonadecatriene. However, a female only lived for 3 to 4 days in a Unitrap whereas the synthetic baits caught males for 7 or 8 weeks. Although the traps with synthetic triene caught more autumn gum moth males than unbaited traps (up to a total of 4 males compared with 0 in the blank traps), the catches in the low-density areas were too small to allow for any statistical comparisons.

In the high population density area the synthetic (3Z,6Z,9Z)-3,6,9-nonadecatriene proved attractive to autumn gum moth males. The traps baited with the triene caught significantly more moths than unbaited traps (Table 2). We only tested virgin females in the high-density area during one night (data not shown), and the only female that emerged caught one male during the first night. The next morning she was dead.

There was no indication in these field trials that either of the alcohols worked synergistically with the triene. That is, the traps with the triene and either of the alcohols did not catch more males than did the triene by itself. Late in the 
Table 1 Catches of male Mnesampela privata attracted by individual virgin females caged in Unitraps in the ACT from February until April 2002. Catches are totals for the 3 to 4 days that the females remained alive in Unitraps

\begin{tabular}{lc}
\hline Females & Number of males caught \\
\hline Female 1 & 48 \\
Female 2 & 4 \\
Female 3 & 3 \\
Female 4 & 2 \\
Females $5,6 \& 7$ & 1 \\
Females $8,9,10,11 \& 12$ & 0
\end{tabular}

season of 2003 we also tested other ratios of the alcohols + triene, but again there was no indication that any of the alcohols worked synergistically.

The (3Z,6Z,9Z)-3,6,9-nonadecatriene also attracted individuals of three closely related species (all belonging to the same subfamily). In the ACT we caught approximately 9 Dolabrossa amblopa Guest and 1 Mnesampela heliochrysa (Lower) and in Victoria we caught 3 M. arida McQuillan.

\section{Discussion}

Through GC and GC-MS analyses, together with GC-EAD and EAG recordings and field screening, we conclude that (3Z,6Z,9Z)-3,6,9-nonadecatriene is a sex pheromone component of $M$. privata. Female pheromone gland extracts also contained two alcohols, namely 1-hexadecanol and 1-octadecanol, but these substances never proved attractive to the males. Both alcohols have previously been recorded in other female moths. 1-hexadecanol has been recorded in females from six different families of Lepidoptera, whereas 1 -octadecanol has been found in three families (El-Sayed 2004; Witzgall et al. 2004). To our knowledge this is the first time that they have been recorded in the sex pheromone gland of a geometrid.

(3Z,6Z,9Z)-3,6,9-nonadecatriene has been recorded as a sex pheromone component in other geometrids (and in other moths, e.g. noctuids) (Millar 2000; El-Sayed 2004; Witzgall et al. 2004). To our knowledge this is the first time that it has been identified in female moths and also proved attractive to males in field when tested on its own. Earlier records have found $(3 Z, 6 Z, 9 Z)-3,6,9$-nonadecatriene to work synergistically or to be a pheromone precursor. Trap catches of both Alsophila pometaria Harris in Canada (Wong et al. 1984) and Peribatodes rhomboidaria Denis \& Schiffermüller in Hungary and Switzerland (Tóth et al. 1987) increased significantly when the triene was added to two tetraenes and one ketone (the main pheromone components), respectively. Similarly, in field trapping in Hungary for three other geometrids (Colotois pennaria Linnaeus, Erannis defoliaria Clerck and Agriopis marginaria Fabricius), adding the triene to the main component produced a more attractive lure than the main component alone (Szöcs et al. 1993). Field catches of Biston robustum Butler in Japan increased when triene was added to a three component blend of diene + two epoxides (Yamamoto et al. 2000), but the catches were low and no statistical analyses were performed.
Table 2 Catches of male Mnesampela privata in traps baited with synthetic (3Z,6Z,9Z)-3,6,9-nonadecatriene ("triene") in Mildura from late January until June, 2003. Totals in the same column with different letters differ significantly $(P<0.05)$ from each other following Kruskal-Wallis tests (followed by MannWhitney U-tests)

\begin{tabular}{lccc}
\hline $\begin{array}{l}\text { Lure } \\
\text { composition }\end{array}$ & $\begin{array}{c}\text { 28 January } \\
\text { to 30 March } \\
(n=7)\end{array}$ & $\begin{array}{c}\text { 31 March } \\
\text { to 11 June } \\
(n=7)\end{array}$ & $\begin{array}{c}\text { 31 March } \\
\text { to 11 June } \\
(n=7)\end{array}$ \\
\hline $\begin{array}{l}\text { Unbaited Unitrap } \\
\text { (blank) }\end{array}$ & $-*$ & $7^{\mathrm{A}}$ & $7^{\mathrm{A}}$ \\
$\begin{array}{l}500 \mu \mathrm{g} \text { triene } \\
1000 \mu \mathrm{g} \text { triene }\end{array}$ & $11^{\mathrm{A}}$ & $92^{\mathrm{B}}$ & - \\
\hline
\end{tabular}

*no blank was used during this period

In closely related geometrids, namely Boarmia (Ascotis) selenaria Schiffermüller and Ascotis selenaria cretacea Butler, (3Z,6Z,9Z)-3,6,9-nonadecatriene has been identified from females but no effect has been found in males in field (Ando et al. 1997) or wind tunnel + field studies (Cossé et al. 1992). It has instead been suggested that the triene acts as a biochemical precursor to the pheromone epoxynonadecadiene (Cossé et al. 1992; Ando et al. 1997). In yet other species of geometrids and noctuids, $(3 Z, 6 Z, 9 Z)$ $3,6,9$-nonadecatriene has proved attractive to males in field screening, but no analyses of female extracts were done (e.g. Szöcs et al. 1984; Subchev et al. 1986; Millar et al. 1990; 1992; Witjaksano et al. 1999). Whether the triene is also a component of the sex pheromones of $M$. arida, $M$. heliochrysa and $D$. amblopa, which we caught in traps containing (3Z,6Z,9Z)-3,6,9-nonadecatriene, also remains to be determined. When employing the screening method for pheromone "identification" some bias is bound to arise based on the choice of compounds tested. Proof of a sex attractant need not mean that the particular compound is used as a sex pheromone (Millar 2000).

It is tempting to speculate that the autumn gum moth probably uses more compounds in its sex pheromone, even though only one EAD-active component was detected. Our field catches were quite poor. Even in the outbreak population, where a light trap regularly caught at least the same number of moths as did our best pheromone trap, pheromone trap catches were low. The findings from some 35 species of geometrid suggest that the triene acts either as a synergist or as the main component (El-Sayed 2004; Witzgall et al. 2004). Consequently, co-occurring moth species must require additional pheromone components to be able to find individuals of the opposite sex. The autumn gum moth is the only native Australian geometrid that has so far been shown to use the triene as a component of its sex pheromone. In fact, $(3 Z, 6 Z, 9 Z)-3,6,9$-nonadecatriene is probably the first identified sex pheromone component of a native Australian geometrid.

There are 3 possible reasons why additional EAD-active components were not detected in our analyses. Firstly, the peak at retention time $19.40 \mathrm{~min}$ (Fig. 1A) may not be homogeneous and a second isomer of $(3 Z, 6 Z, 9 Z)-3,6,9$ nonadecatriene may be superimposed. However, such an isomer, coinciding precisely with the $(3 Z, 6 Z, 9 Z)$-standard 
over a range of phase polarities, has not been recorded in the literature. Secondly, the additional component may be too fragile to survive the refinement process or the GC conditions. However, such a chemical would not be typical of other lepidopteran pheromone structures. Thirdly, the additional component (or components) may be formed enzymatically from the triene or the alcohols on the surface of the gland before release as effluvium and therefore would be barely represented in solvent extracts. We consider this possibility to be the most likely alternative and that the trapped effluvium could reveal its identity by GC-MS and GC-EAD. However, M. privata females were loathe to display calling behaviour under laboratory conditions and therefore it was not possible to entrap the effluvium, e.g. within capillary tubes (Lacey \& Saunders 1992).

As for using pheromone traps to monitor populations of autumn gum moth, this study has brought us much closer to an alternative to light trapping. However, additional studies are needed to improve our knowledge of the sex pheromone of this moth and its efficacy in mate location. We have only begun the process of developing a sex pheromone-based monitoring system for $M$. privata. We are continuing our collaborative research to address outstanding issues.

\section{Acknowledgments}

We thank Testu Ando, Ken Dickson, Peter Ebner, Ted Edwards, William Foley, Wittko Francke, Peter McQuillan, Michelle Michie, Rod Peakall, Luke Rapley and Rob Rhind for their advice and assistance. FÖ and MJS would particularly like to thank the CF Lundströms Stiftelse and Hellmuth Hertz Foundation (financial support) as well as the Swedish and Australian Embassies because without their combined assistance FÖ would not have been able to come to Canberra to collaborate with MJS and his Australian colleagues on this project. August 2002 to August 2003 was a year of good research, great company and enjoyable cultural exchanges.

\section{References}

Abbott I (1993) Insect pest problems of eucalypt plantations in Australia. 6. Western Australia. Aust For 56: 381-384

Ando T, Ohtani K, Yamamoto M, Miyamoto T, Qin X-R, Witjaksono (1997) Sex pheromone of Japanese giant looper, Ascotis selenaria cretacea: identification and field tests. J Chem Ecol 23: 2413-2423

Bashford R (1993) Insect pest problems of eucalypt plantations in Australia. 4. Tasmania. Aust For 56: 375-377

Bestmann HJ, Michaelis K, Vostrovsky O, Schäfer HJ, Michaelis, R (1987) Synthese Methylen-unterbrochener Lepidopteren Polyenpheromone und strukturanaloger Acetylensynthese, Wittig-Reaktion und Kolbe-Elektrolyse. Liebigs Ann Chem 5: 417-422

Cossé AA, Cyjon R, Moore I, Wysoki M, Becker D (1992) Sex pheromone component of the giant looper, Boarmia selenaria Schiff. (Lepidoptera: Geometridae): identification, synthesis, electrophysiological evaluation, and behavioural activity. J Chem Ecol 18: 165-181

Elliott HJ, Bashford R (1978) The life history of Mnesampela privata (Guen.) (Lepidoptera: Geometridae) a defoliator of young eucalypts. J Aust ent Soc 17: 201-204
Elliott HJ, McArthur C, Floyd RB, de Little D (eds) (2000) Proceedings of a workshop on managing pests of eucalypt plantations. AUS-Hobart: CRC for Sustainable Production Forestry

El-Sayed AM (2004) The Pherobase. Extensive Database of Insect Pheromones and Semiochemicals. http://www.pherobase.com (updated 2004-03-07)

Kabalka GW, Varma M, Varma RS, Srivastava PC, Knapp FF Jr (1986) The tosylation of alcohols. J Org Chem 51: 2386-2388

Lacey MJ, Saunders CJ (1992) Chemical composition of sex pheromone of Oriental fruit moth and rates of release by individual female moths. J Chem Ecol 18: 1421-1435

McQuillan PB (1985) A taxonomic revision of the Australian autumn gum moth genus Mnesampela Guest (Lepidoptera: Geometridae, Ennominae). Entomol scand 16: 175-202

Millar JG (2000) Polyene hydrocarbons and epoxides: a second major class of lepidopteran sex attractant pheromones. Annu Rev Entomol 45: 575-604

Millar JG, Giblin M, Barton D, Underhill EW (1990) (3Z,6Z,9Z)nonadecatriene and enantiomers of (3Z,9Z)-cis-6,7-epoxynonadecadiene as sex attractants for two geometrid species and one noctuid moth species. J Chem Ecol 16: 2153-2166

Millar JG, Giblin M, Barton D, Underhill EW (1992) Sex pheromone components of the two geometrid moths Lobophora nivigerata and Epirrhoe sperryi. J Chem Ecol 18: 1057-1068

Neumann FG (1993) Insect pest problems of eucalypt plantations in Australia. 3. Victoria. Aust For 56: 370-374

Neumann FG, Collett NG (1997) Insecticide trials for control of the autumn gum moth (Mnesampela privata), a primary defoliator in commercial eucalypt plantations prior to canopy closure. Aust For 60: 130-137

Phillips CL (1993) Insect pest problems of eucalypt plantations in Australia. 5. South Australia. Aust For 56: 378-380

Rubottom GM, Kim C (1983) Preparation of methyl ketones by the sequential treatment of carboxylic acids with methyllithium and chlorotrimethylsilane. J Org Chem 48: 1550-1552

Steinbauer MJ (2002) Oviposition preference and neonate performance of Mnesampela privata in relation to heterophylly in Eucalyptus dunnii and E. globulus. Agric For Entomol 4: $245-253$

Steinbauer MJ (2003) Using ultra-violet light traps to monitor autumn gum moth, Mnesampela privata (Lepidoptera: Geometridae), in south-east Australia. Aust For 66: 279-286

Steinbauer MJ, Matsuki M (2004) Suitability of Eucalyptus and Corymbia for Mnesampela privata (Guenée) (Lepidoptera: Geometridae) larvae. Agric For Entomol 6 (in press)

Steinbauer MJ, McQuillan PB, Young CJ (2001) Life history and behavioural traits of Mnesampela privata that exacerbate population responses to eucalypt plantations: comparisons with Australian and outbreak species of forest geometrid from the northern-hemisphere. Aust Ecol 26: 525-534

Stone C (1993) Insect pest problems of eucalypt plantations in Australia. 2. New South Wales. Aust For 56: 363-369

Subchev MA, Ganev JA, Vostrowsky O, Bestmann HJ (1986) Screening and use of sex attractants in monitoring of geometrid moths in Bulgaria. Z Naturforsch 41: 1082-1086

Szöcs G, Tóth M, Bestmann HJ, Vostrowsky O (1984) A twocomponent sex attractant for males of the geometrid moth Alsophila quadipunctata. Entomol exp appl 36: 287-291

Szöcs G, Tóth M, Francke W, Schmidt F, Philipp P, König WA, Mori K, Hansson BS, Löfstedt C (1993) Species discrimination in five species of winter-flying geometrids (Lepidoptera) based on chirality of semiochemicals and flight season. J Chem Ecol 19: 2721-2735

Tóth M, Szöcs G, Francke W, Guerin PM, Arn H, Schmid A (1987) Field activity of sex pheromone components of Peribatodes rhomboidaria. Entomol exp appl 44: 199-204

Whittle CP, Bellas TE, Bishop AL (1991) Sex pheromone of lucerne leafroller, Merophyas divulsana (Walker) (Lepidoptera: Tortricidae): evidence for two distinct populations. J Chem Ecol 17: $1883-1895$

Witjaksono, Ohtani K, Yamamoto M, Miyamoto T, Ando T (1999) Response of Japanese giant looper male moth to synthetic sex pheromone and related compounds. J Chem Ecol 25: 1633-1642 
Witzgall P, Lindblom T, Bengtsson M, Tóth M (2004) The Pherolist. www-pList of sex Pheromones of Lepidoptera Sveriges Lantbruksuniversitet, Alnarp. http://www.pherolist.slu.se/ (updated 2004)

Wong JW, Palaniswamy P, Underhill EW, Steck WF, Chisholm MD (1984) Novel sex pheromone components from the fall crankerworm moth, Alsophila pometaria. J Chem Ecol 10: $463-473$

Received 19 March 2004; accepted 9 June 2004.
Yamamoto M, Kiso M, Yamazawa H, Takeuchi J, Ando T (2000) Identification of chiral sex pheromone secreted by giant geometrid moth, Biston robustum Butler. J Chem Ecol 26: $2579-2590$

\section{(1) To access this journal online: \\ (4) http://www.birkhauser.ch}

